\title{
Designing Inquiry-based Laboratory on Concave Eyeglasses Experiment to exercise Student's Science Inquiry Skills
}

\author{
Setiya Utari ${ }^{1}$, Eka Cahya Prima ${ }^{2}$ \\ \{ setiyautari@upi.edu ${ }^{1}$, ekacahyaprima@upi.edu ${ }^{2}$ \} \\ Department of Physics Education, Faculty of Mathematics and Science Education, Universitas \\ Pendidikan Indonesia, Bandung, Indonesia ${ }^{1}$, Department of Science Education, Faculty of Mathematics \\ and Science Education, Universitas Pendidikan Indonesia, Bandung, Indonesia ${ }^{2}$
}

\begin{abstract}
This paper is aimed to design and to implement an inquiry-based laboratory model and cookbook experiment model on a new simple concave eyeglasses experiment in Indonesia. The model is a part of experiment models contributing to developing standardization of national experiment examination through the revised 2013 curriculum framework. The model has been successfully applied to K-11 in a Private Senior High School. The best achievement of the model is very high with (0.92) item validity as much as its reliability, good $(0.50)$ discrimination power, and medium (0.64) difficulty index. The average student can achieve $72 \%$ of the experiment process test including finding problems, tools, method, procedure, data, analysis, and conclusion. We concluded that several competencies can be trained by using inquiry-based laboratory experiments, including understanding experimental problem, determining innovative tools needed, choosing an appropriate method, composing the experiment procedure, collecting data, analyzing data, and writing conclusion.
\end{abstract}

Keywords: Inquiry-based Laboratory, Cookbook based Laboratory, Concave eyeglasses experiment

\section{Introduction}

Wenning [1] stated that content knowledge and science process skills, as part of proper science instruction, are not effectively achieved through "teaching by telling" method. He offered an inquiry learning approach through laboratory activity. This inquiry activity has essential roles in physics. It is now accepted that the laboratory has become an integral part of science education [2],[3] He also reveals that short lesson length, inefficient equipment, inadequate in-service training of teachers will decrease the performance of physics laboratories. Wenning [4] affirms that laboratory experiment is necessary to construct student's logic and to connect to his verification.

Optical experiments are already well-known for students. Drovak [5] denotes that attracted experiments of life phenomenon can improve students' interest as well as teachers', so that demonstration of life phenomenon can be carried out through inquiry-based teaching. Moreover, students can learn the scientific way of knowing the natural world through inquiry activities [4]. Douglas [6] also investigated student's understanding of the optical application with simple equipment to analyze light propagation through a mask. The outcome revealed 
that physics with calculus-based and algebra-based course, without laboratory activity and demonstrations, resulted in unmemorable concept.

Physics teachers in Indonesia have not yet taught a part of an optical experiment, especially concave lenses experiment, because of lack of experimental tools. Learning by doing" science experiment is an effective method to enhance scientific concepts and life skills so that teachers must develop attractive innovative tools by themselves to conduct a memorable process of physics learning [7]. We assumed that this concave eyeglasses experiment through inquiry-based laboratory model is a better experiment model to enhance inquiry skills than traditional model through cookbook based laboratory model [8].

Understanding science processes emerges not the only teacher but also student by defining a problem, hypothesizing from an evidence base, creating an experiment, identifying and controlling variables, collecting, representing the graph, and interpreting data, conducting error analyses, drawing conclusions, and communicating results [1],[2]. Inquiry activity deals with engaging students in active learning and including real-world applications in the learning process. One of the important things, while teacher is experimenting, is students' awareness of the worthwhile experiment for their life [9]. Moreover, Fang [10] reveals that student's motivation and learning experience in inquiry is better when teachers are attentive to students.

Dermott [11] said that the innovative model with a reasonable assessment through active learning could be contributed to curriculum development. Considering that the optical physics chapter in Indonesian curriculum 2013 expects teacher's competency to break down student's curiosities and their life-problem-solving skills, this model is relevant to be applied in our curriculum.

\section{Research Method}

This research was conducted to develop a new inquiry-based laboratory model and cookbook experiment model, especially for a concave eyeglasses experiment. A quasiexperimental design with control group was adopted. The test was given to student at K-11 private senior high school. It is designed to analyze student inquiry activity, such as how to understand problems, how to choose experiment properties, how to select method, and how to list procedures to analyze data and arrange conclusion. This research was compared with cookbook materials. It contains three questions about data, analysis, and conclusion. Test results were analyzed following validity, reliability, discriminating power, and difficulty level. The complete supplementary data regarding the instrument can be accessed through the link http://bitly/instrument-concavelens .

\section{Result and Discussion}

A concave lens always forms a virtual image, so that we need something to find the image length. A real image may be obtained if a virtual object is used, and a converging lens can be used to provide such object, as shown in Figure 1. 


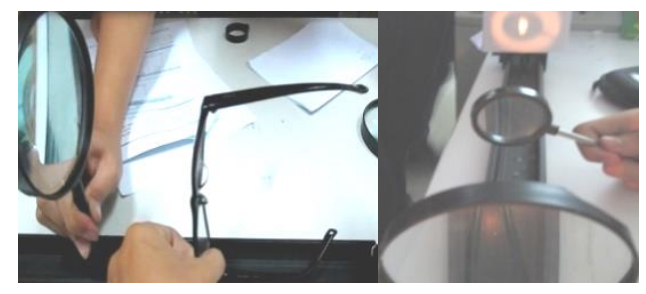

Fig. 1. Experiment setting to find eyeglasses power.

Object $S$ is placed at a distance from $M$ greater than its focal length so that a beam converging to point $\mathrm{O}$ is obtained. $\mathrm{O}$ is thus the virtual object for the diverging lens $\mathrm{L}$ placed as shown in Figure 2, and the real image $I$ can be obtained. $I$ is farther away from $\mathrm{L}$ and $\mathrm{O}$, since the concave lens makes the incident beam on it diverge more.

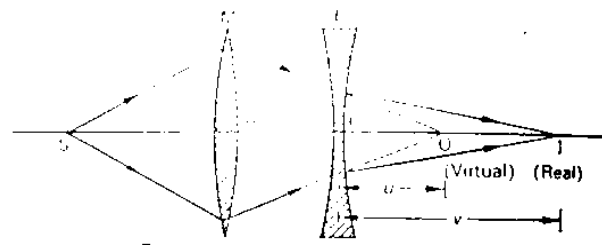

Fig. 2. The focal length on the diverging lens.

The image distance $v$, from the diverging lens, is $\mathrm{CI}$ and can be measured. The object distance $u$, from this lens $=\mathrm{CO}=\mathrm{AO}-\mathrm{AC}$, and $\mathrm{AC}$ can be measured. The length of $\mathrm{AO}$ is obtained by removing lens L, leaving the converging lens, and writing the position of the real image now formed at $\mathrm{O}$ by lens $\mathrm{M}$. Thus, $u(=\mathrm{CO})$ can be found, since $\mathrm{O}$ is a virtual object for the concave lens. Substitute for $u$ and $v$ in equation (1) to find the focal length

$$
\frac{1}{v}+\frac{1}{u}=\frac{1}{f} \text { or } f=\frac{u \cdot v}{u+v}
$$

After implementing the inquiry-based laboratory and cookbook based laboratory, we evaluated the instrument as shown in Table 1 and also found senior high school students characteristics of inquiry activities as shown in Figure 3.

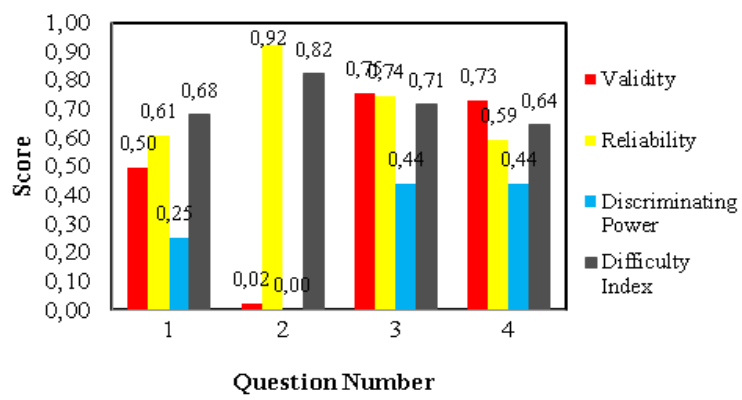

Fig. 3. Assessment analysis for inquiry-based laboratory. 
Table 1. Assessment data on inquiry-based laboratory and cookbook laboratory.

\begin{tabular}{cccccccc}
\hline \multirow{2}{*}{ Type* } & \multirow{2}{*}{ Number } & \multicolumn{2}{c}{ Validity } & \multicolumn{2}{c}{ Reliability } & \multicolumn{2}{c}{ Discriminating Power } \\
\cline { 3 - 7 } & & Value & Interpretation & Value & Interpretation & Value & Interpretation \\
\hline A & 1 & 0.50 & Medium & 0.61 & High & 0.25 & Medium \\
& 2 & 0.02 & Very low & 0.92 & Very high & 0.00 & Bad \\
& 3 & 0.75 & High & 0.74 & High & 0.44 & Good \\
& 4 & 0.73 & High & 0.59 & Medium & 0.44 & Good \\
B & 1 & 0.92 & Very high & 0.62 & High & 0.50 & Good \\
& 2 & 0.90 & Very high & 0.71 & High & 0.44 & Good \\
& 3 & 0.80 & Very high & 0.67 & High & 0.31 & Medium \\
\hline
\end{tabular}

\begin{tabular}{cccccc}
\hline \multirow{2}{*}{ Type* $^{*}$} & \multirow{2}{*}{ Number } & \multicolumn{2}{c}{ Difficulty Index } & \multicolumn{2}{c}{ Mean Score } \\
\cline { 3 - 6 } & & Value & Interpretation & Score & Mark \\
\hline A & 1 & 0.68 & Medium & 2.71 & 68 \\
& 2 & 0.82 & Easy & 3.29 & 82 \\
& 3 & 0.71 & Easy & 2.86 & 71 \\
& 4 & 0.64 & Medium & 2.57 & 64 \\
B & 1 & 0.64 & Medium & 2.57 & 64 \\
& 2 & 0.77 & Easy & 3.07 & 77 \\
& 3 & 0.75 & Easy & 3.00 & 75 \\
\hline
\end{tabular}

*Type $A$ is the inquiry-based laboratory assessment and type $B$ is the cookbook laboratory assessment

The first item in our inquiry process assessment defines how the student can find the science problem. The result indicates that item validity is medium $(0.50)$, item reliability is high (0.61), discriminating power is medium (0.25), and difficulty index is medium (0.68). We conclude that this question is suitable to measure student competency in finding the problem.

The second item which denotes how the student can select an experiment tool shows very low validity (0.02), very high item reliability (0.92), bad discriminating power (0.00), and easy difficulty index (0.82). We conclude that very low validity and very high reliability are certainly unsuitable for measuring student competence to select experiment tools. Finding out the experimental tools is very easy due to tools availability at laboratory. Therefore, an alternative question that has more challenges to seek is necessary to improve the quality of test items.

The third item defines how the student chooses a method to attack problems. The result indicates that item validity $(0.75)$ is as high as its reliability $(0.74)$, discriminating power is good $(0.44)$, but difficulty index is easy $(0.71)$. We conclude that this question is adequately suitable to measure student competency in choosing the experimental method.

The fourth item defines how student explains a procedure to clarify his experimental activity. The result indicates that item validity is high $(0.73)$, item reliability is medium $(0.59)$, discriminating power is good (0.44), and difficulty index is medium (0.64). We conclude that this question is suitable to appraise student competence in explaining the experimental procedures.

According to our data and interpretations, we promote our physics experiment assessment through inquiry activity as a pure physics experiment model for senior high school students. Furthermore, a few improvements in our model can make it better.

Our experimental investigation is not only inquiry-based laboratory but also cookbook based laboratory. We evaluated its instrument as shown in Figure $\mathbf{4}$ and also found student 
characteristics at senior high school in order to obtain their experimental reports, including data, analysis, and conclusion.

The first number on this verification based process defines how the student can take the experimental data and completely write them on a working sheet. The result indicates that item validity is very high $(0.92)$, item reliability is high $(0.62)$, discriminating power is good (0.50), and the difficulty index is medium (0.64). We conclude that this question is suitable to analyze student competence in writing data.

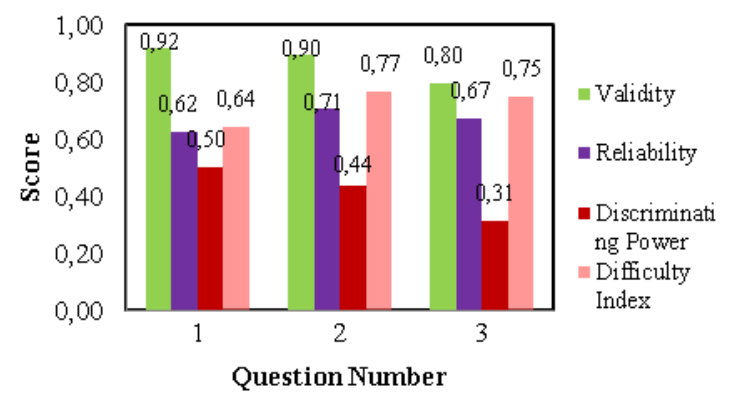

Fig. 4. Assessment analysis for cookbook based laboratory.

The second number of the test, which defines how the student can analyze the experiment data, has a very high validity (0.90), high item reliability $(0.71)$, good discriminating power (0.77), and easy difficulty index (0.82). We conclude that this question is sufficiently suitable to evaluate student competence to analyze the experimental data.

The third number question defines how students can compose their preliminary conclusion. The result indicates that its item validity is very high $(0.80)$, item reliability is high (0.67), discriminating power is medium (0.31), and difficulty index is easy (0.73). We analyze this easiness of this item due to the providence of assessment material, which was included ahead of a worksheet. The activity is guided by both manual books and to facilitate student to be able to attack the problem quickly. However, we conclude that this question is suitable to evaluate student competency in composing the conclusion.

We note and pay attention to inquiry-based laboratory compared with cookbook laboratory. Firstly, students who studied through inquiry approach were slightly confused at the beginning of the section to find a procedure to attack the problem, so that teacher's more attention to student was an important thing to handle it. Our expectation is the same as the explanation of Douglas [6]. Secondly, inquiry-based laboratory model has provided an attractive thing to develop more student's inquiry competences started from finding eyeglasses problem to a conclusion. Taylor and Dana [12] revealed that problem instruction has given a meaningful context. The result of the experimental activity result was also investigated. The mean score data is presented in Figure 5.

All data could be interpreted as follows: most students $(68 \%)$ could understand the experimental problem, almost entire students $(82 \%)$ could determine properties of experiment that they need, most students $(71 \%)$ could choose an appropriate method to solve problems, most students (64\%) could compose the procedure to attack the problem, most students (64\%) could completely collect data needed for more investigation, almost entire students (77\%) were able to analyze data, whether the result was accurate or not, and most students (75\%) 
obtained conclusion which answered the experiment purposes. The final result found was that most students $(72 \%)$ could learn through these experiment models.

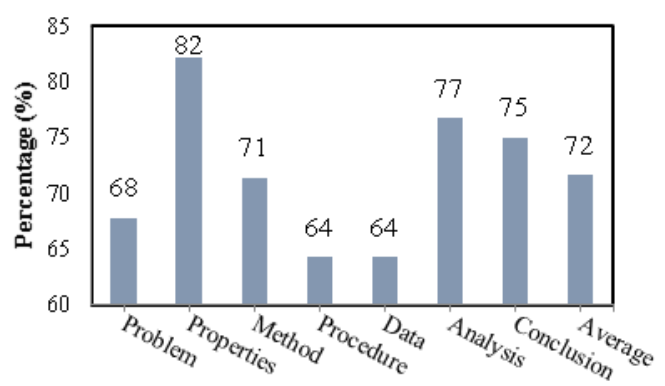

Fig. 5. Student competence profile in experimental activity.

\section{Conclusion}

According to our investigation, we revealed that an inquiry-based laboratory model could be implemented in senior high school as a real-life based physics experiment model. Several competencies were constructed, including understanding the experimental problems, determining experimental tools needed, choosing an appropriate method, composing the experiment procedure, collecting data, analyzing data, and writing the conclusion. We suggest improving the test continuously and applying the same material at several schools to obtain more detailed characteristics.

\section{References}

[1] Wenning, C. J.: Implementing inquiry-based instruction in the science classroom: A new model for solving the improvement-of-practice problem. Journal of Physics Teacher Education Online, 2(4), pp. 9-15 (2005)

[2] Prima, E. C., Karim, S., Utari, S., Ramdani, R., Putri, E. R. R. and Darmawati, S. M.: Heat Transfer Lab Kit using Temperature Sensor based ArduinoTM for Educational Purpose. Procedia Engineering, 170, pp. 536-540 (2017)

[3] Prima, E. C., Utari, S., Chandra, D. T., Hasanah, L. and Rusdiana, D.: Heat and temperature experiment designs to support students' conception on nature of science. JOTSE: Journal of technology and science education, 8(4), pp. 453-472 (2018)

[4] Wenning, C. J.: Experimental inquiry in introductory physics courses. Journal of Physics Teacher Education Online, 6(2), pp. 2-8 (2011)

[5] Dvořák, L.: Low-Cost Electrostatic Experiments. Latin American Journal of Physics Education. 6 (1), pp. 153-158 (2012)

[6] Douglas, E. P. and Chiu, C.C.: Implementation of Process Oriented Guided Inquiry Learning (POGiL) in engineering. Advances in Engineering Education. pp. 1-16 (2013)

[7] Choi, A., Seung, E. and Kim, D.: Science Teachers' Views of Argument in Scientific Inquiry and Argument-Based Science Instruction. Research in Science Education, pp. 1-18 (2019)

[8] Fletcher, K., McLean, J., Sells, R., Rommel-Esham, K. and Showers, D.: The Build-it, Leave-it, Teach-it Program: A Model for Recruiting and Retaining Pre-service Physics Teachers. The Physics Teacher, 57(6), pp. 409-412 (2019) 
[9] Yeung, A., Cornish, S., Kable, S. and Sharma, M. D.: What Can Instructors Focus on when Improving Undergraduate Science Experiments? Supporting a Cross-Disciplinary Approach. International Journal of Innovation in Science and Mathematics Education (formerly CAL-elaborate International), 27(3) (2019)

[10] Fang, H. and Lin.: The Impact of Expectancy-value, Learning Experience, and School Environment on High School Students' Science Inquiry Competence Performance. International Journal of Humanities and Management Science. 1(1), pp. 45-47 (2013)

[11] Dermott, L. C.: Curriculum Development and The Assessment Of Student Learning: An Example from The Work-Energy and Impulse-Momentum Theorems. Investigações em Ensino de Ciências. 2(1), pp. 27-42 (1997)

[12] Taylor, J. A. and Dana, T. H.: An illustration of the complex nature of subject matter knowledge: A case study of secondary school physics teachers' evaluation of scientific evidence. Journal of Physics Teacher Education Online. 1(4) pp. 3-13 (2003) 